\title{
ISABEL MORGAN Y EL GRUPO DE INVESTIGACIÓN SOBRE VACUNAS DE LA UNIVERSIDAD JOHNS HOPKINS (1940-1960): UN MODELO DE ANÁLISIS DE LA TRAYECTORIA DE UNA MUJER EN EL MUNDO DE LA CIENCIA ${ }^{1}$
}

ROSA BALLESTER

Universidad Miguel Hernández (Elche)

\section{INTRODUCCIÓN}

La situación actual de las mujeres en el sistema de ciencia y tecnología europeo-occidental es un tema candente y de interés creciente como se pone de manifiesto, por ejemplo, por el hecho de que la Red Europea de Evaluación de la Tecnología (ETAN: European Technology Assessment Network) creara un Grupo de trabajo sobre las mujeres y la ciencia, que elaboró un interesante informe ${ }^{2}$ cuyo objetivo era promover la excelencia mediante la integración de la igualdad entre géneros. Su significado es realmente importante porque supone no sólo poner de relieve la infrarrepresentación de las mujeres en el ámbito de la ciencia, la tecnología y el desarrollo, sino introducir, de hecho, el tema del género en la política científica de los estados de la UE. En cuanto a los contenidos de la publicación, además de examinar la situación de la mujer en estos ámbitos, se formulan recomendaciones específicas a una amplia gama de organismos entre los que se incluyen la Comisión, el Parlamento Europeo, los estados miembros y las organizaciones que forman, financian y emplean a las personas consagradas a la investigación científica. En el horizonte de este informe del año 2001, se preveía que el trabajo realizado por el Grupo de expertas de ETAN desempeñara un papel importante en el desarrollo y la ejecución de las políticas a favor

1. Trabajo realizado en el marco del proyecto HUM2005-07378-C03-01/HIST, financiado por el Ministerio de Educación y Ciencia.

2. EUR 19319: Política científica de la Unión Europea: promover la excelencia mediante la integración de la igualdad entre géneros, Luxemburgo, Oficina de publicaciones oficiales de las Comunidades Europeas, 2001. 
de las mejores prácticas, con el objeto de contribuir a que Europa saque todo el partido posible a sus recursos humanos en investigación.

En el ámbito del Estado español, es destacable el trabajo realizado por la Comisión "Mujeres y Ciencia», creada en 2001 en el seno del Consejo Superior de Investigaciones Científicas, que ha dado lugar a una serie de publicaciones e informes que recogen los resultados de los trabajos llevados a cabo por sus integrantes, entre los que destacan la elaboración de algunos informes ${ }^{3}$ y la aparición de un número monográfico de la revista Arbor ${ }^{4}$. La participación de investigadoras del CSIC en foros internacionales sobre esta temática es también cada vez mayor, como se pone de relieve en el reciente documento preparado por Álvarez Marrón ${ }^{5}$. La página web elaborada por este grupo de trabajo del CSIC es un excelente lugar donde poder seguir el tema de forma actualizada ${ }^{6}$.

El objetivo que pretendemos alcanzar en este trabajo es ofrecer algunas de las claves interpretativas que nos ayuden a entender esta todavía escasa presencia (cuantitativa y, sobre todo, cualitativamente) de mujeres en el ámbito de la ciencia y la técnica, recurriendo a la historia como instrumento de análisis de problemas actuales. Y para ello vamos a hacer referencia especial a la figura de Isabel Morgan, como ejemplo paradigmático, dentro de la investigación básica y experimental sobre la vacuna contra la poliomielitis. El interés del tema viene dado también, de forma adicional, porque aunque, como veremos más tarde, la historiografía de la enfermedad poliomielítica es abundante, no existen trabajos específicos desde la perspectiva que queremos contemplar aquí.

Previamente, sin embargo, parece obligado comentar una serie de cuestiones que son necesarias para poder contextualizar nuestro análisis. Nos referiremos, en primer lugar, al entramado ideológico que aparece en los discursos que la biología y la medicina hicieron, durante siglos, sobre la naturaleza femenina $y$, en segundo lugar, nos acercaremos a la realidad de alguna de las mujeres que se acercaron al mundo de la ciencia en el periodo de la Revolución Científica que nos ayuden a comprender mejor la situación de Isabel Morgan, tres siglos más tarde.

\section{EL FUNDAMENTO BIOLÓGICO DE DIFERENCIAS Y DESIGUALDADES ENTRE HOMBRES Y MUJERES Y SU REPERCUSIÓN SOBRE LAS TRAYECTORIAS PROFESIONALES}

Desde la década de 1980, y aún con anterioridad, el número de trabajos que se han ocupado de la construcción de la naturaleza femenina, desde la biología y la medicina, y su relación con la actividad científica profesional a lo largo de

3. PéREZ SENDEÑo, Eulalia: La situación de las mujeres en el sistema educativo de ciencia y tecnología en España y su contexto internacional, Madrid, MEC, 2003.

4. FernÁndez VARGAS, Valentina; SANTESMASES, María Jesús: «Ciencia y tecnología en el CSIC: una visión de género", Arbor, CLXXII (2002), pp. 455-677.

5. ÁLVAREZ MARRÓN, Joaquina: Informe-Resumen sobre el Congreso Internacional "Women in Science: the way forward" celebrado en Heidelberg, del 9 al 11 de mayo de 2007", Madrid, CSIC, 2007.

6. http://www.csic.es/mujer_ciencia.do (consultado el 13 de diciembre de 2007). 
Isabel Morgan y el grupo de investigación sobre vacunas de la universidad Johns...

la historia es extraordinariamente elevado e imposible de reproducir aquí en su integridad. Es suficiente mencionar algunos de los últimos estudios realizados en España que, además tienen el interés añadido de recoger de forma sistemática la bibliografía existente y ofrecer una síntesis de los principales hallazgos que en este terreno se han realizado?.

Como es bien sabido, la aparición de la Ginecología como especialidad médica con todos los criterios que las ciencias sociales consideran indispensables para su institucionalización (enseñanza reglada, instituciones profesionales, monopolio de una parcela del saber y la práctica) tuvo lugar en el siglo XIX, aunque con anterioridad, desde los inicios de la biología y la medicina en el área Occidental en la Grecia Clásica, se contaba con abundante material empírico y con hipótesis y modelos sobre el funcionamiento del cuerpo femenino.

Muy sucintamente, se puede hablar de la existencia de tres grandes modelos en los textos científicos: los modelos de la inferioridad, de la diferencia y de la ciencia positiva, sucesivamente. El primero, vigente desde el siglo V a.C. hasta el periodo renacentista, subraya diferencias cualitativas entre los dos sexos: la mujer, fría y húmeda según la teoría humoral vigente, era biológicamente inferior al varón desde la fecundación, debido a que poseía un exceso de fluidos y por la influencia del útero en todo su organismo (uterocentrismo). Esta inferioridad biológica hace que en ella predominen los aspectos instintivos y no los racionales. A esta imagen, de procedencia aristotélico-galénica, la escolástica medieval añade la connotación negativa de pecadora: Eva incitó a pecar a Adán y su subordinación deriva de ese pecado. El segundo periodo (siglos XV a XVIII), en el mundo moderno ${ }^{8} \mathrm{y}$, especialmente, en el periodo ilustrado, la naturaleza femenina es precisada con gran detalle y la razón fija unas pautas que pueden verse, por ejemplo, en los artículos específicos de L'Enciclopédie de Diderot y D'Alambert, en los escritos del conde de Buffon, en la obra de Rousseau $y$, por supuesto, en los textos médicos. Nos encontramos aquí con dos aspectos claramente diferenciados: por un lado, se asiste a un interés creciente por el tema de la mujer y ya no se habla de inferioridad sino de complementariedad de la inteligencia del hombre, y de la sensibilidad y belleza de la mujer, más

7. BOLUfer, Mónica: Mujeres e Ilustración: la construcción de la feminidad en la España del siglo XVIII, València, Institució Alfons el Magnànim, 1998; MAGALLÓN, Carmen: Pioneras españolas en las ciencias. Las mujeres del Instituto Nacional de Física y Química, Madrid, CSIC, 1999; MIQUeO, Consuelo et al. (eds.): Perspectivas de género en salud, Madrid, Biblioteca Nueva-Minerva, 2001; JUfRESA, Montserrat (coord.): Dossier: "Mujer y medicina en el Mundo Antiguo», Arenal, 7 (2000), pp. 267-358; CABRÉ, Montserrat y ORTIZ GÓMEZ, Teresa (eds.): Sanadoras, matronas y médicas en Europa, siglos XII-XX, Barcelona, Icaria, 2001; ORTIZ GÓMEZ, Teresa: «El papel del género en la construcción histórica del conocimiento científico de la mujer», en Elvira Ramos (ed.): La salud de las mujeres: hacia la igualdad de género en salud, Madrid, Ministerio de Trabajo y Asuntos Sociales- Instituto de la Mujer, 2002, pp. 29-47. ORTIZ GómEZ, Teresa: Medicina, Historia y Género.130 años de investigación feminista, Oviedo, KRK, 2006; ORTIZ, Teresa: «Las mujeres en las profesiones sanitarias», en Isabel Morant (dir.): Historia de las mujeres en España y América Latina, Madrid, Cátedra, 2006, pp. 523-546; DeLGADO ECHEVARRÍA, Isabel: El descubrimiento de los cromosomas sexuales, Madrid, CSIC, 2007.

8. MACLEAN, Ian: The Renaissance notion of woman, Cambridge, Cambridge University Press, 1980. 
cercana a la naturaleza. Pero, por otro lado, dicha toma de conciencia invalida a ésta última: su debilidad biológica y su sensibilidad externa la incapacitan para la vida pública y profesional, para la instrucción avanzada. La mujer está hecha para el interior, para llevar una vida protegida, pero dependiente ("dulce sujeción» de la que hablaba el enciclopedista Virey). Su perspectiva es el matrimonio y la maternidad, su anatomía y su fisiología están claramente destinadas a esta finalidad.

A lo largo del siglo XIX y los inicios del XX la «naturaleza femenina», tradicionalmente definida, resistió mal los avances de las ciencias positivas. Por ejemplo, la teoría evolucionista de Charles Darwin chocaba abiertamente con la idea de una naturaleza femenina inmutable y universal, y en el mundo de la antropología física y de la medicina comenzó a gestarse un fuerte debate sobre estas cuestiones de desigualdades y diferencias físicas. De este modo, fue decayendo paulatinamente el discurso de la debilidad observándose, por ejemplo, que conforme mejoraban las condiciones de vida y los cambios técnicos en el embarazo y parto - procesos fisiológicos que eran los responsables del incremento importante de morbi-mortalidad por enfermedades infecciosas, en especial, la temida «fiebre puerperal»- la esperanza de vida para las mujeres era más alta que en el caso de los hombres; las medidas craniométricas, o las teorías sobre las funciones cerebrales, tampoco permitían invalidar el cerebro femenino. En el área de la patología, la histeria, enfermedad "típicamente femenina», se define en términos psiquiátricos como una afección que afectaba a hombres y mujeres, y no debida a la influencia del útero sobre el resto de los órganos, aparatos y sistemas, característica que daba el perfil peculiar a la fisiología y fisiopatología de las mujeres, como se había considerado con anterioridad.

A partir de esos momentos y coincidiendo, como hemos dicho, con la aparición de la Obstetricia y Ginecología y con el desarrollo científico-tecnológico de muchas áreas biomédicas, se asiste a un importante despegue de conocimientos y de aplicación de técnicas diagnósticas y terapéuticas de gran relevancia y prestigio social, sobre todo en el área de la reproducción. Pese a ello, aún hacia 1960 es posible encontrar elementos residuales de estos desfavorables elementos ideológicos en los cuales se pretende justificar, con argumentos científicos o pseudo científicos, determinadas formas de entender la sociedad y el papel que la mujer debía desempeñar en ella9.

\section{CIENTÍFICAS PIONERAS EN LA HISTORIA. LAS MUJERES EN LAS ACADEMIAS CIENTÍFICAS. EL CASO DE MARÍA WINKELMANN (1670- 1720)}

A lo largo del siglo XVII, como es bien sabido, el largo proceso de tradición y cambio, de polémicas entre antiguos y modernos en lo tocante a la nueva visión

9. Vide, por ejemplo, el capítulo consagrado a la ginecología psicosomática en el influyente tratado de Botella Llusiá, José: Tratado de Ginecología. Tomo I. Fisiología Femenina, Barcelona, Ed. Científico Médica, 1968. 
Isabel Morgan y el grupo de investigación sobre vacunas de la universidad Johns...

de la naturaleza por parte de la ciencia y a un cambio sustancial en objetivos y métodos, desembocará en lo que se ha rotulado como "Revolución Científica». Pese a todos los matices que a este proceso se han dado por parte de corrientes historiográficas criticas como el constructivismo social, puede decirse que una nueva visión del mundo produjo un despliegue fundamental para el desarrollo de la ciencia y la técnica occidentales. En gran medida, los núcleos de mayor relevancia en esta historia estuvieron fuera del ámbito universitario, excesivamente rígido y dogmático, creciendo en el seno de instituciones creadas ex profeso, como la «Royal Society» londinense (1662), La "Académie des Sciences» francesa (1666) o la "Berliner Akademie des Wisenschaft» (1700).

Las mujeres, sin embargo, no llegaron a pertenecer como miembros de estas instituciones hasta tres siglos más tarde, en pleno siglo XX. La Royal Society admitió en 1945 a dos científicas, Marjory Stephenson y Kathleen Londsdale, y la prestigiosa academia parisina no contó entre sus miembros de derecho a una mujer hasta 1979. En el caso de España, todavía habría que esperar a 1987, con la entrada de María Cascales en la Academia de Farmacia y de Margarita Salas en la Real Academia de Ciencias Físicas, Exactas y Naturales, en $1988^{10}$. Es sobradamente conocida la historia de Marie Curie, la primera persona a quien se concedieron dos Premios Nobel, que fue rechazada en su tiempo para entrar en la academia francesa, pese a su enorme prestigio intelectual ${ }^{11}$.

Un ejemplo paradigmático de esta situación ha sido estudiado muy en profundidad por Londa Schiebinger ${ }^{12}$. Se trata de alemana María Winckelmann, quien pidió el ingreso en la academia berlinesa en 1712. María, que había nacido en 1670, cerca de Leipzig, era hija de un pastor luterano quien cuidó su educación y fue responsable de su temprano interés por la astronomía. Hay que tener en cuenta que, en aquel momento, gran parte de la instrucción en los aspectos prácticos de esta actividad científica corría a cargo de artesanos e ingenieros que construían instrumentos para la observación astronómica, aunque también hay que decir que tanto en esta área, como en otras relativas a la nueva ciencia, fueron en realidad el resultado de la fusión de una triple tradición: la práctica, ya citada, la tradición humanística y la lógico-matemática propia del escolasticismo aristotélico medieval. El astrónomo era tanto un teórico como un técnico. En cualquier caso, el desarrollo científico fue posible por la nueva y positiva valoración de la técnica frente a la situación anterior, que separaba claramente entre la esfera de saberes teóricos y la de los aspectos aplicados, despreciando a estos últimos como "artes serviles» propias de estamentos sociales inferiores.

En este contexto, hubo no pocas mujeres trabajando en talleres y en ellos sus contribuciones - como las de los varones- dependieron menos de la lectura de

10. http://www.fmujeresprogresistas.org/visibili3.htm (consultada el 20 de diciembre de 2007).

11. ALIC, Margaret: Hypatia's Heritage. A history of Women in Science from Antiquity to the XIXth Century, Boston, Beacon Press, 1986.

12. SCHIEBINGER, Lorna: "María Winkelmann at the Berlin Academy. A turning point for women in science", Isis, 78 (1987), pp. 174-200. 
libros y más de las innovaciones prácticas en el cálculo o la observación. Sabemos que la participación de las mujeres entre 1650 y 1720 fue alrededor de un $14 \%$ entre las personas que realizaban observaciones astronómicas, sin duda la cifra más alta de toda Europa. Sin embargo, la exclusión de las mujeres de las universidades acrecentaba las diferencias en cuanto al nivel de instrucción entre uno y otro sexo. De haber nacido hombre, María muy probablemente hubiera continuado sus estudios en Leipzig o Jena, como lo hizo su propio marido, el también importante astrónomo Gottfried Kirch.

La exclusión de las mujeres de las universidades, aunque limitaba su participación en la astronomía, no las excluía enteramente puesto que, en gran medida, las grandes discusiones científicas en esos momentos se produjeron en lugares diferentes de la institución universitaria, como, por ejemplo, los observatorios astronómicos privados, cuya puerta les era abierta habitualmente a través de sus padres o maridos, como fue el caso de María. Gracias a ello pudo, por ejemplo, descubrir en 1702 un cometa hasta entonces desconocido y de cuya prioridad no hay duda ninguna, aunque para dar publicidad a su hallazgo tuvo que utilizar el nombre de su marido. Pese a que más adelante publicó algunos trabajos con su propio nombre sobre diversos temas y participó en la reforma del calendario de la Academia berlinesa, no consiguió que se le aceptara en dicha institución cuando intentó ingresar, en 1712, ocupando la plaza de su marido, fallecido años antes. María luchó no sólo por obtener unos honores, más que merecidos, sino para poder vivir de su trabajo. En la introducción de una de sus obras científicas, citando textos bíblicos comentaba: «El sexo femenino, como el masculino, posee los talentos de la mente y el espíritu que Dios les ha dado. Con esfuerzo y estudio, una mujer puede llegar a ser tan hábil como un hombre en la observación y conocimiento del firmamento» ${ }^{13}$.

Como en el caso de María, la ausencia de representación femenina en las academias científicas no puede ser entendida simplemente por la inexistencia de mujeres con un nivel científico suficiente, sino que la exclusión fue la resultante de una política llevada a cabo conscientemente y que se expresaba de forma explícita, en los estatutos fundacionales de dichas instituciones. Más adelante, la profesionalización de la actividad científica hizo desaparecer los talleres artesanales a los que hacíamos referencia arriba, el único lugar posible de formación de las mujeres en estas actividades científico-técnicas, y con la creciente separación entre la esfera privada familiar y el espacio público y profesional fueron éstas confinadas al rol doméstico durante muchos años, prácticamente hasta el siglo XX. De hecho, con los cambios en la estructura social de la ciencia y su enseñanza, la participación de las mujeres cambió cuando comenzaron a ser formalmente admitidas en las universidades a partir de 1860 en Gran Bretaña y una década más tarde en Francia y Alemania. Pero también se abría una segunda opción y era la de continuar participando en el trabajo científico de padres, hermanos o maridos, como ayudantes de investigación invisibles al exterior, sin

13. Ibíd., p. 177. 
Isabel Morgan y el grupo de investigación sobre vacunas de la universidad Johns...

dejar el ámbito doméstico. Esta opción, no infrecuente, vendrá a ser, de algún modo, el reflejo del legado histórico de la tradición artesanal.

Un ejemplo del proceso de incorporación de las mujeres a los estudios universitarios en medicina es el caso español, estudiado magníficamente por Teresa Ortiz ${ }^{14}$ y por Carmen Álvarez Ricart ${ }^{15}$, quien realizó su tesis doctoral sobre este tema (en aquel momento, 1969, totalmente inédito) bajo la dirección de J.M. López Piñero en la Universidad de Valencia. Estos trabajos nos han permitido conocer de qué modo se fue produciendo dicha incorporación en España. Con un cierto retraso con respecto a otros países europeos, fue en la década de 1880-1890 cuando aparecen las primeras mujeres en carreras de medicina en la Universidad de Barcelona. Álvarez Ricart, haciendo un seguimiento del periodismo médico de la época, ha podido contrastar las opiniones de los médicos con respecto de sus compañeras que fueron, en general, negativas. También Consuelo Flecha recoge el proceso en detalle. La presión social exigía una mayor capacidad intelectual para las mujeres que se atrevían a dar ese paso. Como ejemplo, el testimonio de Margarita Nelken en 1922: "Mientras que en los estudiantes varones cabe todo, entre nuestras estudiantes no caben hoy día más que aplicadas, muy aplicadas, de ahí que puede verse con qué brillantez cursan los estudios más áridos» ${ }^{16}$. Las argumentaciones utilizadas en apoyo de los que se oponían a la entrada de las mujeres en el mundo de la profesión médica- no así en la de enfermería, considerada tradicionalmente como una profesión "adecuada» a la condición femenina-carecían de fundamentos rigurosos y estaban relacionadas con problemas de posibles competencias profesionales y con el temor de que esta situación actuara como revulsivo del papel de la mujer en la sociedad. "La mujer, absorbida hasta ahora por el hogar doméstico, al verse dueña de la libertad hace lo que los pueblos ignorantes y mal aconsejados cuando se sacuden la opresión: malversan esta libertad y la convierten en motivo de descrédito" ${ }^{17}$.

Pese a todo, el número de mujeres en la carrera de medicina fue creciendo a lo largo del siglo XX. En España, en 1920, era muy escaso el porcentaje de estudiantes de medicina del sexo femenino (solo un 1\%). Y una década más tarde, sólo 50 médicas ejercían en todo el estado. Sin embargo, a partir de los años 1970, el ascenso fue imparable, siendo en 1990 un 50\% del total de estudiantes de medicina y un 19\% de los profesionales que ejercían la medicina, con una tendencia al alza, existiendo una clara asociación entre grado de desarrollo so-

14. Cabré, Montserrat y OrTIZ GÓmEZ, Teresa (eds.): Op.cit.; OrTIZ GómEZ, Teresa: Medicina, Historia y Género..., op.cit.; ORTIZ, Teresa: «Las mujeres en las profesiones sanitarias», op.cit.

15. AlVAREZ RICART, Carmen: La mujer como profesional de la medicina en el siglo XIX, Barcelona, Anthropos, 1988.

16. NeLKEN, Margarita: La condición social de la mujer en España, Barcelona, Minerva (Reprint: 1975), p. 54.

17. Cfr. ÁlVAREZ RiCART, Carmen: «Algunas opiniones sobre el estudio de la medicina por la mujer durante el siglo XIX en España", Actas del III Congreso Nacional de Historia de la Medicina, Valencia, Sociedad Española de Historia de la Medicina, 1969, p. 36. 
cial y económico y participación de las mujeres. Otra cosa son los problemas a los que aludíamos al principio y que no han desaparecido del todo.

Vamos ahora a acercarnos a un caso contemporáneo que pensamos puede ser ilustrativo y motivo de reflexión.

\section{EL PROBLEMA DE LA POLIOMIELITIS Y LOS GRUPOS DE INVESTIGACIÓN. LA FIGURA DE ISABEL MORGAN (1911-1996)}

Las décadas centrales del siglo XX asistieron en España a un recrudecimiento de las cifras de morbilidad y mortalidad por poliomielitis $\mathrm{y}$, por tanto, de sus temidas secuelas. La crisis epidémica más importante fue la de 1959, cuando se declararon oficialmente 2132 casos de poliomielitis paralítica. Esta situación no fue, como es bien sabido, un patrimonio exclusivo de España o de los países mediterráneos: los países nórdicos, Centroeuropa o Gran Bretaña ${ }^{18}$ padecieron también esta enfermedad, por no hablar de Estados Unidos, cuyas epidemias de polio han sido especialmente bien estudiadas, sin duda por la inmensa repercusión social y mediática que allí tuvieron, a lo que no fueron ajenos dos hechos: que el propio presidente, F.D. Roosevelt, padeciera la enfermedad y, en segundo término, por tratarse del país en el cual se crearon las vacunas que, finalmente, se extendieron al resto del mundo ${ }^{19}$. De hecho, se habla de dos tipos de experiencias diferentes según las diferentes tradiciones científicas, en relación con los enfoques de la investigación sobre la enfermedad en Europa y en USA.

La historia reciente de la poliomielitis ha estado claramente influida por la estrategia, promovida por la OMS, de la erradicación de la enfermedad para el año 2000. La Global Polio Erradication Iniciative constituye, en sí misma, un hito histórico por tratarse de la campaña sanitaria más amplia, en el ámbito internacional, que se haya desarrollado nunca y, de hecho, se considera como un modelo a seguir en otro tipo de inmunizaciones como las relativas al VIH. Por otro lado, la historia de la poliomielitis ha sido contemplada frecuentemente como un ejemplo paradigmático de conquista de la Humanidad frente a la enfermedad, con el poder de la ciencia. Desde 1970, sin embargo, ya habían comenzado los historiadores a cuestionar esta imagen idílica y a abordar, de

18. Citamos, por su interés, el reciente trabajo de: LINDNER, Ulrike y BLUME, Stuart: "Vaccine innovation and adoption: Polio Vaccines in the UK, the Netherlands and West Germany, 19551965", Med. Hist., 50 (2006), pp. 425-446, que tiene, además, la ventaja de recoger gran parte de la bibliografía europea sobre el tema, mucho más escasa que la publicada en Estados Unidos. En dicho trabajo se considera fundamental la realización de análisis comparados entre diferentes países con el objeto de estudiar las respuestas nacionales, muchas veces muy diferentes, ante una misma innovación científica como es el desarrollo de una vacuna.

19. Entre los más significativos: WILSON, Don: «A crippling fear: experiencing polio in the era of FDR", Bull.Hist.Med., 72 (1988), pp. 464-495. ROGERS, Naomi: Dirt and disease: Polio before FDR, New Brunswick, Rutgers University Press, 1992; Gould, Anthony: A summer plague: polio and its survivors, New Haven/ London, Yale University Press, 1995; BLACK, Karl: In the shadow of Polio: a personal and social history, Reading, Addison-Wesley, 1996; SASS, Edmund: Polio's legacy. An oral history, Lanhan/ London, University Press of America, 1996. SHeLl, Marc: Polio and its aftermath. The paralysis of culture, Cambridge, Harvard U.P., 2005. 
Isabel Morgan y el grupo de investigación sobre vacunas de la universidad Johns...

forma rigurosa y crítica, el proceso complejo del origen, desarrollo y erradicación de la enfermedad, incluyendo las disputas científicas y los conflictos de intereses científicos, políticos y económicos. Desde la historia de las vacunas, también se aprecian enfoques interesantes que ayudan a enmarcar los aspectos específicos relativos a la parálisis infantil ${ }^{20}$. Sin embargo, solamente hay menciones tangenciales, desde el punto de vista de las relaciones de género, en el caso de los grupos de investigación que trabajaron de forma muy intensa para poder llevar a cabo una prevención eficaz frente a la temida enfermedad.

De todos los grupos de investigadores que, en varios lugares (Suecia, Alemania, Francia, Gran Bretaña o USA), estaban trabajando para obtener una vacuna antipoliomielítica, el grupo mejor posicionado para poder desarrollar una vacuna realmente efectiva contra la poliomielitis era el que trabajaba en la Johns Hopkins University. Las cabezas del mismo fueron David Bodian, Howard Howe e Isabel Morgan. En los años cuarenta, miembros de este grupo habían podido determinar cuál era la ruta de entrada de los poliovirus, la vía digestiva, mediante la realización de una serie de ensayos experimentales que acabaron de romper con la hipótesis explicativa vigente que indicaba que era la vía respiratoria la puerta de entrada de los gérmenes. El tema no era banal porque las medidas preventivas y las estrategias terapéuticas eran diferentes en uno u otro caso. Estos investigadores fueron también los primeros en predecir que, al menos, existían tres tipos serológicos de virus y mostrar, junto a otra investigadora, Dorothy Horstman, que en el desarrollo de la enfermedad había una breve pero fundamental "fase virémica», en la cual el virus se expandía, a través del torrente sanguíneo, hacia el sistema nervioso central ${ }^{21}$.

Todavía más allá, las investigaciones de este grupo introdujeron en los trabajos experimentales a una nueva especie, el chimpancé. Se gastaron muy importantes sumas de dinero para comprar y mantener este tipo de primates, y los resultados fueron espectaculares ya que el modelo experimental con estos animales mostraba similitudes con el modelo humano de transmisión de la enfermedad.

Isabel comenzó a trabajar en el seno de este grupo de la Johns Hopkins en 1944 en Baltimore. Era hija de un biólogo muy importante, Thomas Hunt Morgan (1866-1945), un genetista que estudió la historia natural, zoología y macromutación en la mosca de la fruta Drosophila melanogaster. Sus contribuciones científicas más importantes fueron en el campo de la Genética. Fue galardonado con el Premio Nobel de Fisiología y Medicina en 1933 por la demostración de que los cromosomas son portadores de los genes. Gracias a su trabajo, la Drosophila melanogaster se convirtió en uno de los principales organismos modelo en Genética.

20. Moulin, Anne-Marie (ed.): L'aventure de la vaccination, Paris, Fayard, 1996.

21. OsHInsKy, David: Polio. An American History. The crusade that mobilized the Nation against the 20th Century most feared disease, Oxford, Oxford University Press, 2005. 
Isabel Morgan se graduó en la Universidad de Stanford e hizo su doctorado en bacteriología en la Universidad de Pennsylvania, antes de unirse al grupo de investigadores del Rockefeller Institute. Tenía una formación muy sólida en técnicas inmunológicas y virología de la polio y la encefalomielitis. Uno de sus maestros, Peter Olitsky, la describía como «una mujer de gran creatividad que no se conforma con aceptar los caminos ya trillados de la investigación sino que busca caminos nuevos, fundamentando sus hipótesis con evidencias científicas sólidas» ${ }^{22}$.

El talento que todos atribuían a Isabel no sirvió para evitar situaciones de discriminación por el hecho de ser mujer. Su salario en el Rockefeller Institute era más bajo que el de sus colegas masculinos y las becas y premios iban invariablemente para ellos. Como testigo coetáneo, el investigador Tom Rivers relataba cómo "pocas mujeres que habían obtenido el grado de doctor y que trabajaron en el Instituto siguieron más allá» ${ }^{23}$. Por eso, el caso de Morgan llamaba la atención porque su camino era un camino de resultados y éxitos en investigación, pese a los problemas citados.

En Johns Hopkins, la investigadora inició una serie de experimentos para inmunizar monos frente a la polio mediante una vacuna de virus inactivados, muertos mediante formaldehido. Además, elaboró una técnica propia que permitía el cultivo de los poliovirus en el sistema nervioso (en cerebro y médula espinal de chimpancés). Los resultados fueron muy prometedores. Los simios vacunados eran refractarios a la enfermedad, a pesar de las altas concentraciones de virus inyectados vivos. La trascendencia de la investigación de Morgan fue fundamental para desarrollar una de las dos líneas de trabajo que condujeron a la virtual desaparición de la parálisis infantil del planeta. El uso de este tipo de inmunización, con la que Jonas Salk, años más tarde, alcanzaría fama mundial al lograr la primera vacuna realmente efectiva contra la poliomielitis y ensayarla a gran escala en USA, era inédita y las primeras hipótesis sobre su efectividad preventiva y los primeros experimentos fueron obra de Isabel.

Pero el camino para la investigadora finalizó aquí. ¿Por qué no fue más allá cuando la parte más difícil de su carrera profesional parecía superada y estaba a las puertas de un éxito evidente? Para entenderlo hay que rastrear en su vida personal. En 1949, en el cénit de su carrera, Isabel dejó el Johns Hopkins al casarse con Joseph Mountain, un coronel de la Air Force que trabajaba en Nueva York. La pareja se mudó a Westchester donde ella, que en aquel momento tenía 36 años, pudo obtener trabajo en un laboratorio infinitamente más modesto del que procedía y cuyos detalles son conocidos a través de la correspondencia de su colega Peter Olitsky con el director del citado laboratorio, quien tenía un nivel muy inferior al de Morgan, y al que Olitsky recomendaba se apoyara en el trabajo de Isabel para llegar a alcanzar niveles más altos en la investigación.

22. OlisTSKY, Peter: «Research: Award Nomination for Isabel Morgan», Peter Olitsky papers, Philadelphia, American Philosophical Society, 1954. Cfr. OSHINSKY, David: Op. cit., p. 131.

23. Beninson, Saul: Tom Rivers: Reflections on a life in Medicine and Science: an oral history memory, Cambridge Mass., MIT, 1967. 
Isabel Morgan y el grupo de investigación sobre vacunas de la universidad Johns...

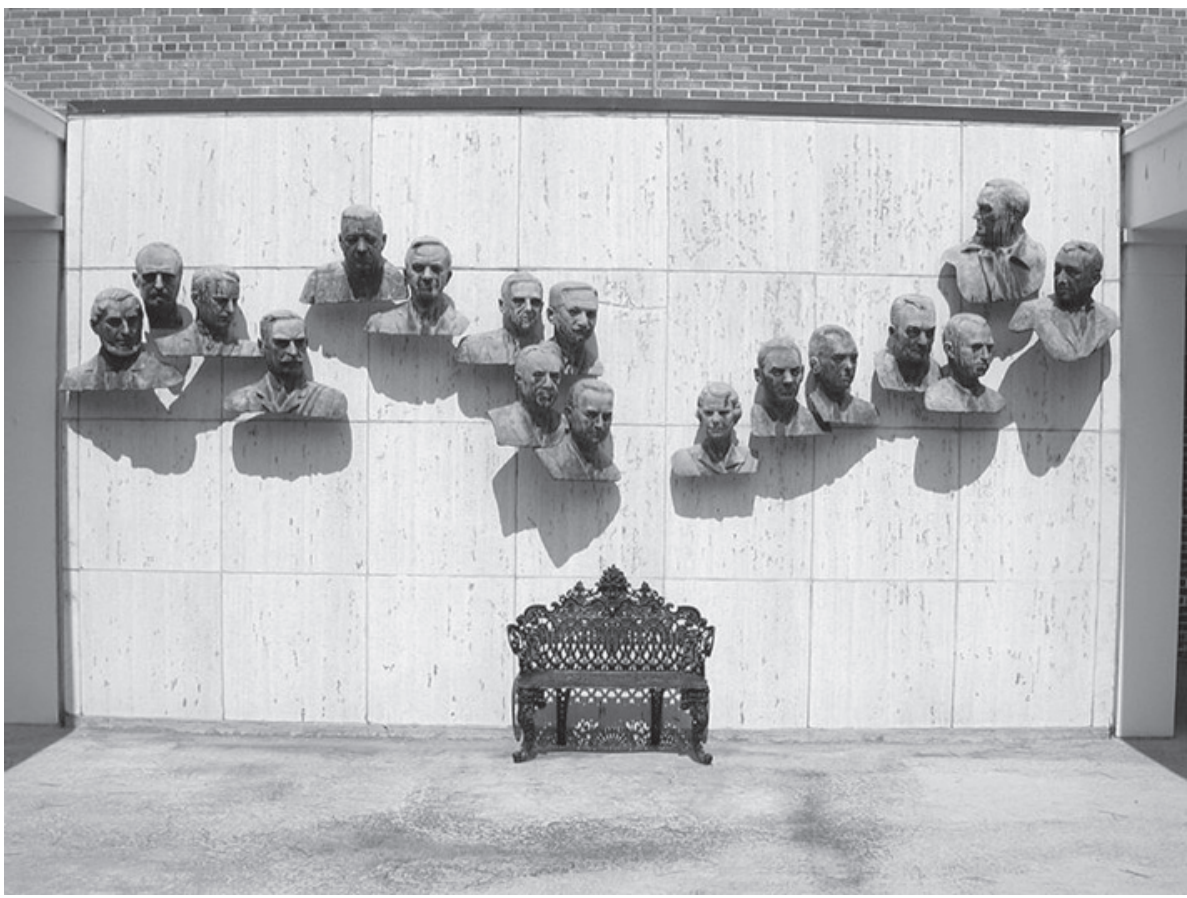

Isabel Morgan es la séptima comenzando por la derecha.

Parte de la historia posterior nos es desconocida, por tratarse de una historia estrictamente privada. De forma paulatina, nuestra investigadora dedicó más y más tiempo a su trabajo en el ámbito doméstico, sobre todo por la responsabilidad que recayó sobre ella cuando decidió ocuparse del hijo pequeño de su marido quien padecía una severa discapacidad. Los testimonios de David Bodian, uno de los componentes de su prestigioso grupo de Baltimore, como hemos comentado antes, permiten entender el significado de este viraje en la vida de Isabel y el contexto en el que se produjo: "Ibby (Isabel) amaba la ciencia pero todavía amaba más a su nueva familia. Sus compañeros contemplaron esta decisión como una gran pérdida para el desarrollo de las investigaciones de laboratorio, pero todo el mundo lo entendió. Una mujer como Ibby tenía por delante una gran decisión que tomar y la tomó» ${ }^{24}$. En aquellos momentos, posiblemente, lo que la sociedad no hubiera entendido es que la decisión hubiera sido proseguir con su carrera.

Tras la marcha de Morgan de la Johns Hopkins nadie había seguido sus investigaciones. Bodian, por ejemplo, estaba más interesado en la anatomía pato-

24. OSHINSKY, David: Op.cit., p. 132. 
lógica de la polio que en el desarrollo de una vacuna, y los otros investigadores del grupo no parecían tener las mismas cualidades y energía.

Si las circunstancias históricas hubieran sido otras, hay pocas dudas sobre el hecho de que, en la carrera por obtener una vacuna contra la poliomielitis con gérmenes inactivados, Morgan hubiera logrado alcanzar la meta en primer lugar, por sus cualidades, por su trabajo y también porque trabajaba en el laboratorio más importante y bien dotado para hacerlo. Morgan poseía los conocimientos, las técnicas y los recursos económicos para llevar a cabo con éxito su vacuna. Sólo había un obstáculo que podía haberla frenado: su resistencia a realizar ensayos clínicos con seres humanos hasta no estar completamente segura de su inocuidad.

Su vida, por otro lado, conoció también la tragedia. Su querido hijastro Jimmy murió en un accidente aéreo sobre la ciudad de Nueva York, mientras volvía a su casa desde su escuela tras unas vacaciones de Navidad. Morgan dejó definitivamente su trabajo y ya nunca volvería a la investigación. La única actividad conocida fue cursar un master en bioestadística en la Universidad de Columbia y su papel como asesora científica del prestigioso Sloan-Kettering Cancer Institute en Manhattan. Murió en 1996. Su busto está esculpido, entre los de otros catorce investigadores (es la única mujer presente allî́) que participaron en la lucha contra la poliomielitis, en el "Polio Hall of Fame» en el Roosevelt Warm Spring Institute for Rehabilitation en la ciudad norteamericana de Georgia. 